\title{
Stereoelectronic properties of five anti-HSV-1 2'-deoxynucleosides analogues with heterocyclic substituents in the 5-position: A comparison with BVDU
}

\author{
Anne Olivier ${ }^{\mathrm{a}}$, Isabelle Creuven ${ }^{\mathrm{a}}$, Christine Evrard ${ }^{\mathrm{a}}$, Guy Evrard ${ }^{\mathrm{a}}$, Magdalena Dory ${ }^{\mathrm{a}}$, Arthur van Aerschot ${ }^{\mathrm{b}}$, Piet \\ Wigerinck $^{\mathrm{b}}$, Piet Herdewijn ${ }^{\mathrm{b}}$, Francois Durant ${ }^{\mathrm{a}}$ \\ ${ }^{a}$ Laboratoire de Chimie Moléculaire Structurale, Facultés Universitaires N.-D. de la Paix, rue de Bruxelles 6, B-5000 Namur, Belgium \\ ${ }^{b}$ Laboratory of medicinal Chemistry, Rega Institute for Medical Research, Katholieke Universiteit Leuven, B-3000 Leuven, Belgium
}

\begin{abstract}
Structural and electronic characteristics of 5-(5-chlorothien-2-yl)-2'-deoxyuridine (I), 5-(furan-2-yl)-2'deoxyuridine (II), 5-(5-bromofuran-2-yl)-2'-deoxyuridine (III), 5-(3-bromoisoxazol-5-yl)-2'-deoxyuridine (V) and 5-(isoxazol-5-yl)-2'-deoxyuridine (IV) have been determined and compared to the BVDU (VI) characteristics in order to explain their respective affinity for the herpes simplex virus type 1 thymidine kinase (TK). Molecular structure of 5-(5-chlorothien-2-yl)-2'-deoxyuridine has been obtained using single crystal X-ray crystallography. Electrostatic potential maps, energy and topology of frontier orbitals were computed at the $a b$ initio MO STO-3G and STO-3G* level. These studies reveal that the electrostatic potential energy maps are clearly dependent on the affinity of the compound for the enzyme.
\end{abstract}

Key words: Antiviral activity; Herpes simplex virus type I; 5-(2-Bromovinyl)-2'-deoxyuridine analogue; Single crystal X-ray diffraction; MO calculation

\section{Introduction}

The herpes simplex virus type 1 (HSV-1) encodes for several virus specific enzymes involved in the nucleoside metabolism, among them thymidine kinase (TK). TK is a crucial enzyme in the salvage pathway for thymidine 5'-O-triphosphate leading to the incorporation of thymidine in DNA. The thymidine kinase from herpes simplex virus type I has been expressed in E. coli, purified and crystallized (Enquist et al., 1979; Sanderson et al., 1988). Also the human cytosol TK gene has been cloned, sequenced and its structure was determined (Bradshaw et al., 1984; Flemington et al., 1987). A theoretical three-dimensional model of the active site of both kinases was developed, based on a structure analysis of various kinases and a comparison with the known structure of reference enzymes (Folkers et al., 1991).

Thymidine kinase is an important enzyme in the pathogenicity of the virus (HSV-1) in humans (Coen, 1991). Thymidine kinase-negative mutants mostly have a reduced pathogenicity. The enzyme is also a key enzyme in the metabolic activation of antiviral agents. The modified nucleosides have a much higher affinity for HSV -1 thymidine kinase than for the cellular thymidine kinase, so that preferential phosphorylation in virus-infected cells occur. HSV-1 thymidine kinase could be a target for drugs which might prevent reactivation of HSV -1 when used prophylactically (Leib et al., 1990).

Therefore it is important to study the structural difference between the human and viral TK and to search for compounds which interact selectively with the viral TK. Recently we discovered a new series of 5-substitued-2'deoxynucleosides which show potent activity and high selectivity against HSV-1 (Wigerinck et al., 1991a,b; Wigerinck et al., 1993). These compounds are selectively phosphorylated by the viral TK (Bohman et al., 1993). In this article we try to correlate the affinity of the compounds for the viral TK with stereoelectronic data. First the crystalline structure of 5-(5-chlorothien-2-yl)-2'-deoxyuridine (I) is discussed. Then, we focus on the electronic properties, i.e., molecular electrostatic potential (MEP), topology and energy of frontiers orbitals, by $a b$ initio molecular orbital (MO) calculations. Also a comparison is made with the structural properties of 5-(-2bromovinyl)-2'-deoxyuridine (VI) which is in vitro one of the most potent HSV-1 inhibitors discovered till now. 


\section{Materials and methods}

\subsection{Compounds}

5-(2-Bromovinyl)-2'-deoxyuridine (BVDU) (Fig. 1, VI) is one of the most potent and selective agents which inhibits the replication of herpes simplex virus type 1 (HSV-1). This selectivity is due to the preferential phosphorylation of BVDU in HSV-1 infected cells by the viral thymidine kinase. However, BVDU is not the only selective anti-HSV-1 agent and replacement of the bromovinyl substituent by several 5-membered heterocycles yielded a new series of selective anti-HSV-1 compounds: 5-(5-chlorothien-2-yl)-2'-deoxyuridine (I), 5-(furan-2-yl)-2'-deoxyuridine (II), 5-(5-bromofuran-2-yl)-2'-deoxyuridine (III) (Wigerinck et al., 1991a), 5(3-bromoisoxazol-5-yl)-2'-deoxyuridine (V) (Wigerinck et al., 1991b) and 5-(isoxazol-5-yl)-2'-deoxyuridine (IV) (Wigerinck et al., 1993) (Fig. 1) were synthesized as described previously. Table 1 presents their affinity against the viral thymidine kinase of HSV-1 (HSV-1 TK) and their antiviral activity.

Fig. 1. (I) 5-(5-chlorothien-2-yl)-2'-deoxyuridine. (II) 5-(furan-2-yl)-2'-deoxyuridine. (III) 5-(5-bromofur-an-2yl)-2'-deoxyuridine. (IV) 5-(isoxazol-5-yl)-2'-deoxyuridine. (V) 5-(3-bromoisoxazol-5-yl)-2'-deoxyuridine. (VI) 5(2-bromovinyl)-2'-deoxyuridine.<smiles>O=c1[nH]c(=O)n(C2CC(O)C(CO)O2)cc1-c1ccc(Cl)s1</smiles><smiles>O=c1[nH]c(=O)n(C2CC(O)C(CO)O2)cc1-c1ccco1</smiles><smiles>O=c1[nH]c(=O)n(C2CC(O)C(CO)O2)cc1-c1ccc(Br)o1</smiles><smiles>O=c1[nH]c(=O)n(C2CC(O)C(CO)O2)cc1-c1ccno1</smiles>

III

IV<smiles>O=c1[nH]c(=O)n(C2CC(O)C(CO)O2)cc1-c1cc(Br)no1</smiles><smiles>O=c1[nH]c(=O)n(C2CC(O)C(CO)O2)cc1/C=C/Br</smiles>

\subsection{X-ray diffraction}

Crystals of 5-(5-chlorothien-2-yl)-2'-deoxyuridine (Fig. 1, I) were obtained by slow evaporation of a solution of this compound in a mixture of ethyl acetate-acetone at room temperature. A colourless, prismatic crystal of 0.32 , $0.22,0.36 \mathrm{~mm}$ was used for X-ray measurements, $D_{m}$ was not measured. A total of 6045 reflections $\left(1^{\circ}<\Theta<25^{\circ}\right)$ were collected on a four-circle Enraf-Nonius diffractometer (CAD-4 system) using $\omega-\Theta$ scans and graphite monochromated MoK $\alpha$ radiation $(\lambda=0.71073 \AA)$, giving 5929 independent reflections $(\operatorname{Rint}=0.012)$ and 5385 observed ones $(I \geq 4 \sigma(I))$. The intensity data were corrected for Lorentz and Polarisation effects and 5381 observed reflections were used during subsequent structure refinement. 
The structure was solved using Direct Methods techniques (SHELX-86 program) (Sheldrick, 1986) followed by difference Fourier syntheses. Refinement was performed by full-matrix least-squares on $F$ with $W=l / \sigma^{2}(F)+$ $0.002 F^{2}$ ] (SHELX-76 program) (Sheldrick, 1976). Non-Hydrogen atoms were refined anisotropically, while Hydrogen atoms were included but not refined. Refinement converged to $R=0.037$ and $R w=0.045$. Goodness of fit $=1.50 .(\Delta / \sigma)_{\max }=0.378$ and $-0.54<\Delta p$ e $\AA^{-3}<1.03$.

The PLATON 92 program (Spek, 1990) was used for molecular geometry and crystal-packing analyses. All spectroscopic figures presented in the results were drawn using the ORTEP program (Johnson, 1976).

Table 1 Anti-HSV-1 activity and affinity for HSV-1 thymidine kinase

\begin{tabular}{|l|c|c|}
\hline Compounds & $\begin{array}{c}\text { HSV-1 Thymidine kinase }{ }^{\mathrm{b}} \mathrm{IC}_{50} \\
(\mu M)\end{array}$ & $\begin{array}{c}\text { HSV-1 (KOS) } \\
(\mu \mathrm{g} / \mathrm{ml})\end{array}$ \\
\hline 5-(2-bromovinyl)-2'-dUrd (VI) & 0.3 & 0.06 \\
\hline 5-(5-chlorothien-2-yl)-2'-dUrd(I) & 2.3 & 0.02 \\
\hline 5-(furan-2-yl)-2'-dUrd (II) & 2.9 & 0.45 \\
\hline 5-(3-bromoisoxazol-5-yl)-2'-dUrd (V) & 34 & 7 \\
\hline 5-(isoxazol-5-yl)-2'-dUrd (IV) & 36 & 0.15 \\
\hline 5-(5-bromofuran-2-yl)-2'-dUrd (III) & 51 & \\
\hline dUrd= deoxyuridine & & \\
\hline
\end{tabular}

${ }^{a}$ Data taken from Wigerinck et al. (1991a,b, 1993). ${ }^{b}$ Data taken from Bohman et al. (1993).

\subsection{Quantum mechanical calculations}

Calculations were realized with optimisation procedure in the framework of the RHF-LCAO-MO-SCF (Restricted Hartree Fock - Linear Combination of Atomic Orbital - Molecular Orbital - Self Consistent Field) formalism. The minimal ST03G (Hehre et al., 1969) basis set was used (i.e., Slater-type orbital (STO) approximated from three least-squares fitted Gaussians). However, in the presence of a sulfur atom, stereoelectronic properties have been performed at the ST03G* (Collins et al., 1976) level. The atomic coordinates of the atoms were obtained by crystallographic data. Only the hydrogen atoms were located at standard distances and angles. The deoxyribose group has been replaced by a methyl group in order to reduce the size of the molecule and time consuming problems. The bielectronic integral cut-off and convergence on the density matrix thresholds have been fixed to $10^{-10}$ and $10^{-8}$, respectively. For all compounds, a geometry optimisation was realized using crystallographic data. An energy difference (about 3-4 kcal) was observed by $180^{\circ}$ rotation of the five-membered ring (Fig. 1). The ah initio calculations were based on the stablest conformation, the torsion angle $(\mathrm{C}(3)-\mathrm{C}(4)-\mathrm{C}(5)-\mathrm{C}(8))$ was $0^{\circ}$ for chlorothienyl (I) (Fig. 1 and 2) and $180^{\circ}$ for furanyl (II), bromofuranyl (III), isoxazolyl (IV) and bromoisoxazolyl (V) (Fig. 1).

All computations have been carried out using the Gaussian 86 program (Frisch et al., 1988) adapted to an IBM 9377/90-FPSM64 computer (running under the VM/ CMS operating system). The molecular electrostatic potential (MEP) values were calculated in selected two-dimensional (2-D) planes using the electrostatic property capabilities implemented into Gaussian 86 (Frisch et al., 1988).

The generation of the electron charge density iso-contour maps has been performed with the MOPLOT (Molecular Orbital Plot) program (Hinde et al., 1988). Beside the wave function, the input consists in the desired molecular orbitals (all of them, or a particular one as the homo or the lumo) and the iso-electron charge density surface or contours values (from 0.005 to 0.050 , step $0.005 \mathrm{e}^{-} / \AA^{3}$ ).

All 2-D iso-potential and iso-electron densities maps were produced with an in-house device interactive contouring program, CPS (Contours Plotting System; Bau-doux and Vercauteren, 1989) developed in Fortran with the IBM graPHIGS Software. 
Fig. 2. Atomic numbering and bond lengths (Á) of both molecules (I) (a and b) in the asymmetric unit. Max. esd's are $0.006 \AA$.<smiles>O=C[C@H]1O[C@@H](n2cc(-c3ccc(Cl)s3)c(=O)[nH]c2=O)C[C@H]1O</smiles>

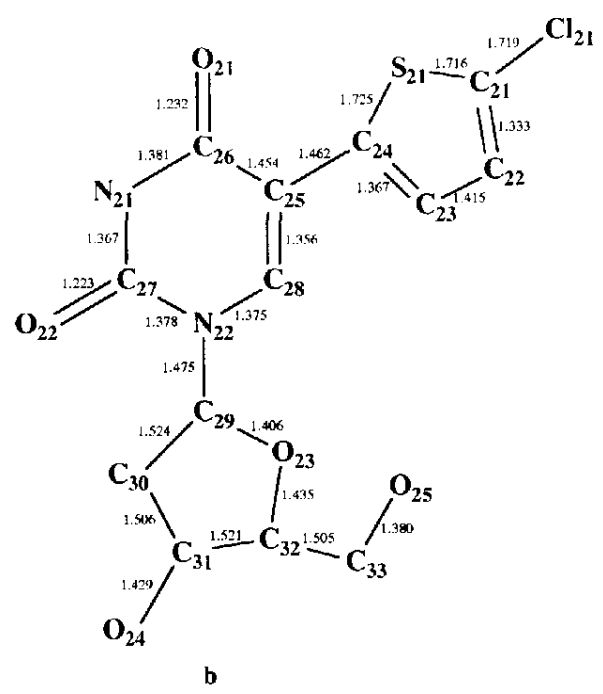

Table 2 Cryslallographic data

\begin{tabular}{|l|c|}
\hline & 5-(5-chlorothien-2-yl)-2'-deoxyuridine (I) \\
\hline Molecular Formula & $\mathrm{C}_{13} \mathrm{H}_{13} \mathrm{~N}_{2} \mathrm{O}_{5} \mathrm{SCl}$ \\
\hline Molecular Weight & 344.8 \\
\hline Crystal System & Monoclinic \\
\hline Space Group & $\mathrm{P} 2_{1}$ \\
\hline $\mathrm{a}(\AA)$ & $9.100(2)$ \\
\hline $\mathrm{b}(\AA)$ & $20.878(3)$ \\
\hline $\mathrm{c}(\AA)$ & $7.837(2)$ \\
\hline$\beta\left({ }^{\circ}\right)$ & $98.572(8)$ \\
\hline $\mathrm{V}\left(\AA^{3}\right)$ & $1472.2(8)$ \\
\hline $\mathrm{Z}$ & 4 \\
\hline Absorption coeff. $\left(\mathrm{cm}^{-1}\right)$ & 4.2 \\
\hline $\mathrm{R}$ & 0.037 \\
\hline
\end{tabular}

\subsection{Molecular graphics}

All superimpositions have been performed with an in-house molecular modeling package KEMIT (Vanderveken et al., 1989) developed with the PHIGS standard for IBM 3179-G terminals and IBM 5080 WORK stations.

\section{Results}

\subsection{Structural analysis}

(1) X-ray diffraction. Atomic parameters of the 5-(5-chlorothien-2-yl)-2'-deoxyuridine (Fig. 1, I) are given in Table 2. Final atomic coordinates and thermal factors are listed in Table 3. There are two molecules in the asymmetric unit. Atoms of the second molecule are numbered from $\mathrm{Cl}(21)$ to $\mathrm{O}(25)$. Atomic numbering and bond lengths are summarized in Fig. 2, valence angles are reported in Fig. 3 and crystal packing is presented in Fig. 4. Crystal data of the other compounds will be soon published. 
For both molecules, the five-membered ring is coplanar to the six-membered ring as shown by the dihedral angles $\mathrm{C}(3)-\mathrm{C}(4)-\mathrm{C}(5)-\mathrm{C}(8)=-0.7(4)^{\circ}$ and $\mathrm{C}(23)-\mathrm{C}(24)-\mathrm{C}(25)-\mathrm{C}(28)=4.2(4)^{\circ}$. This planarity is closely linked to some contacts $\mathrm{O}(1)^{\cdots} \mathrm{S}(1)$ and $0(21) \mathrm{S}(21)$, as revealed by a shorter value than the van der Waals contacts: $\mathrm{O}(1){ }^{\cdots} \mathrm{S}(1)=2.840(2) \AA \hat{~}$ and $\mathrm{O}(21){ }^{\cdots} \mathrm{S}(21)=2.845(2) \AA \hat{~}($ van der Waals contacts $\mathrm{S} \cdots \mathrm{O}=3.25 \AA \hat{)}$ ). The $\mathrm{S} \cdots \mathrm{O}$ interaction between a pair of non-bonded fragments of a molecule are known and discussed (Lozac'h, 1971) but not yet fully understood. The quantum chemical interpretation of the nature of the $\mathrm{S}{ }^{\cdots} \mathrm{O}$ interactions has to be attempted using the $a b$ initio SCF-MO method (Angyan, 1987). The non-bonded SO interactions fall in the critical region between 2.0 and 3.0 Á, which is not covered by any known type of S-O bonding. The structure of 5-(5-chlorothien-2-yl)-2'-deoxyuridine (I) is part of a particular class of compounds characterized by a planar, conjugated five-membered "ring", closed by the non-bonded sulfur and oxygen atoms (Fig. 5) (Angyan, 1987). It seems that the S...O distances in the range 2.0-3.0 $\AA$ are not accidental. They correspond to alterations in the environments of positively charged bi- or quadrivalent $\mathrm{S}$ atoms and the electron-attracting $\mathrm{O}=\mathrm{Y}$ moieties closing five-membered heterorings (Kalman and Parkanyi, 1980).

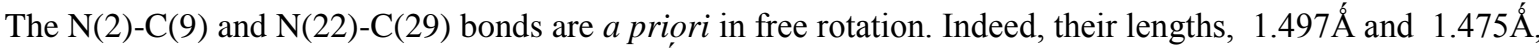
respectively, are significantly longer than $1.33 \AA$ as expected for a standard $\mathrm{C}\left(\mathrm{sp}_{2}\right)-\mathrm{N}$ bond. Moreover, the dihedral angles vary from one molecule to another $\left(\mathrm{C}(7)-\mathrm{N}(2)-\mathrm{C}(9)-\mathrm{C}(10)=87.1(3)^{\circ}\right.$ and $\mathrm{C}(27)-\mathrm{N}(22)-\mathrm{C}(29)$ $\left.\mathrm{C}(30)=123 \cdot 1(3)^{\circ}\right)$.

There is a dense network of hydrogen bonds which stabilizes the crystallographic packing. The pattern is identical for the two molecules (Table 4). Notice particularly that the asymmetric unit is formed by dimers of which the formation is due to hydrogen bonds (Table $4, *$ ) between nitrogen $\mathrm{N}(1)$ of the first molecule and oxygen $\mathrm{O}(22)$ of the second (and vice versa between $\mathrm{N}(21)$ of the second and oxygen $\mathrm{O}(1)$ of the first). Fig. 6 presents a stereoview of dimers with ellipsoids of vibration.

One can observe a parallel arrangement of the plane parts of the molecules, uracil cycle of one in front of thiophenyl cycle of another and vice versa. The relatively short distance between the cycles, $3.9 \AA$, is characteristic of a II-II interaction which could lead to a charge transfer between the considered partners.

Molecular structures of the 5-(5-chlorothien-2-yl)-2'-deoxyuridine (I) and of the BVDU (VI) (Parkanyi et al., 1983) may be compared by molecular superimpositions. Fig. 7 shows that the two conformationally restricted compounds are very similar. The bromovinyl group is quasi coplanar with the uracil cycle (Parkanyi et al., 1987), then, a good superimposition of the six-membered cycles of the two molecules and of the bromovinyl and the five-membered cycle of 5-(5-chlorothien-2-yl)-2'-deoxyuridine are observed. The orientation of the deoxyribose is variable as we pointed out before.

(2) Steric effect. There are considerable differences in the five-membered cycle of the five 2'-deoxynucleosides structures. Each one has one or two heteroatoms, and three of them are substituted by an halogen atom. The crystallographic data show two particular orientations for the five-membered cycle. For chlorothienyl (I), this cycle is in such a position that the sulfur atom is situated in front of the oxygen atom (Fig. 2, 021) of the sixmembered cycle. In contrast, for furanyl (II), bromoisoxazolyl (V), isoxazolyl (IV) and bromofuranyl (III), the heteroatoms point in the opposite direction of the oxygen atom (Fig. 2, 021). We suppose that these differences could explain partially the structure-affinity relationships of the compounds. Therefore, we studied the van der Waals envelopes of these molecules and we compared these data with those obtained for BVDU (VI). No representative conclusions appeared in this comparison, it seems that the orientation of the five-membered ring and the position of the heteroatoms in the cycle are more important than the van der Waals envelopes. 
Table 3 Final atomic coordinates $\left(\times 10^{4}\right)$ and $B_{e q}$ values with esd's in parentheses $\left(B_{c q}=8 \pi^{2} U_{e q}\left(\dot{A}^{2}\right)\right.$ and $U_{e q}=$ $\left.1 / 3 \sum i \sum_{j} u_{i j} a_{i}^{*} a_{j}^{*} a_{i} a_{j}\right)$ for 5-(5-chlorothien-2-yl)-2'-deoxyuridine (I).

\begin{tabular}{|c|c|c|c|c|}
\hline & $\mathrm{x} / \mathrm{a}$ & $y / b$ & $\mathrm{z} / \mathrm{c}$ & $\mathrm{B}_{\mathrm{eq}}$ \\
\hline$\overline{\mathrm{Cl}(1)}$ & 3377 (1) & $4950(1)$ & $1547(1)$ & $4.36(1)$ \\
\hline $\mathrm{C}(\mathrm{l})$ & $4621(2)$ & $4420(1)$ & 903 (2) & $2.86(3)$ \\
\hline $\mathrm{C}(2)$ & 4495 (2) & 3784 (1) & $824(4)$ & $3.27(4)$ \\
\hline$C(3)$ & $5730(2)$ & 3496 (1) & $232(4)$ & $2.96(4)$ \\
\hline $\mathrm{C}(4)$ & 6779 (1) & 3924 (1) & $-111(2)$ & $2.22(3)$ \\
\hline$S(1)$ & $6230(1)$ & 4697 (1) & $265(1)$ & $2.71(1)$ \\
\hline$C(5)$ & 8203 (1) & 3777 (1) & $-705(2)$ & $2.07(3)$ \\
\hline$C(6)$ & $9232(2)$ & $4276(1)$ & $-1028(2)$ & $2.30(3)$ \\
\hline $\mathrm{O}(\mathrm{l})$ & 9047 (1) & 1854 (1) & $-824(2)$ & $3.48(3)$ \\
\hline $\mathrm{N}(1)$ & $10502(1)$ & 4060 (1) & $-1614(2)$ & $2.48(3)$ \\
\hline$C(7)$ & 10879 (1) & 3435 (1) & $-1887(2)$ & 2.08 \\
\hline $\mathrm{O}(2)$ & $12042(1)$ & 3282 (1) & $-2401(2)$ & $2.98(3)$ \\
\hline$N(2)$ & $9872(1)$ & 2990 (1) & $-1516(2)$ & $2.21(3)$ \\
\hline $\mathrm{C}(8)$ & $8583(2)$ & 3163 (1) & $-945(2)$ & $2.39(3)$ \\
\hline $\mathrm{C}(9)$ & $10239(2)$ & $2300(1)$ & $-1740(2)$ & $2.54(3)$ \\
\hline $\mathrm{O}(3)$ & 8909 (1) & 1952 (1) & $-2038(2)$ & $3.16(3)$ \\
\hline$C(10)$ & $11160(2)$ & $2020(1)$ & $-137(4)$ & $3.61(4)$ \\
\hline $\mathrm{C}(11)$ & $10590(4)$ & 1337 (1) & $-106(4)$ & $3.78(5)$ \\
\hline $\mathrm{O}(4)$ & $11387(2)$ & 950 (1) & $-1148(4)$ & $5.34(5)$ \\
\hline$C(12)$ & 8967 (4) & $1406(1)$ & $-929(4)$ & $3.62(5)$ \\
\hline $\mathrm{C}(13)$ & $7846(5)$ & $1445(1)$ & $293(5)$ & $5.40(7)$ \\
\hline $\mathrm{O}(5)$ & 8235 (4) & 1951 (1) & 1449 (4) & $6.42(6)$ \\
\hline C1 (21) & $11293(1)$ & $3216(1)$ & 3223 (1) & $5.33(1)$ \\
\hline $\mathrm{C}(21)$ & $9988(2)$ & 3747 (1) & $3751(2)$ & $3.33(4)$ \\
\hline$C(22)$ & $10120(2)$ & $4383(1)$ & 3809 (4) & $3.82(5)$ \\
\hline$C(23)$ & $8863(2)$ & $4671(1)$ & $4356(4)$ & $3.52(4)$ \\
\hline $\mathrm{C}(24)$ & 7795 (2) & 4244 (1) & $4663(2)$ & $2.43(3)$ \\
\hline$S(21)$ & 8352 (1) & 3471 (1) & 4318 (1) & $2.97(1)$ \\
\hline$C(25)$ & $6370(1)$ & 4395 (1) & $5217(2)$ & $2.15(3)$ \\
\hline $\mathrm{C}(26)$ & $5353(2)$ & 3901 (1) & $5626(2)$ & $2.28(3)$ \\
\hline $\mathrm{O}(21)$ & $5544(1)$ & 3321 (1) & $5450(2)$ & $3.32(3)$ \\
\hline $\mathrm{N}(21)$ & $4100(1)$ & $4120(1)$ & $6244(2)$ & $2.29(3)$ \\
\hline$C(27)$ & 3711 (1) & 4742 (1) & $6488(2)$ & $2.11(3)$ \\
\hline $\mathrm{O}(22)$ & 2595 (1) & 4893 (1) & $7092(2)$ & $2.95(3)$ \\
\hline $\mathrm{N}(22)$ & $4672(1)$ & 5191 (1) & $5992(2)$ & $2.28(3)$ \\
\hline $\mathrm{C}(28)$ & $5950(2)$ & $5013(1)$ & $5375(2)$ & $2.33(3)$ \\
\hline $\mathrm{C}(29)$ & $4314(2)$ & $5878(1)$ & $6054(2)$ & $2.38(3)$ \\
\hline $\mathrm{O}(23)$ & $4212(1)$ & $6128(1)$ & $4373(1)$ & $3.16(3)$ \\
\hline $\mathrm{C}(30)$ & $5503(2)$ & 6273 & $7160(4)$ & $3.30(4)$ \\
\hline $\mathrm{C}(31)$ & $5385(2)$ & 6915 (1) & 6269 (4) & $3.27(4)$ \\
\hline $\mathrm{O}(24)$ & $4286(2)$ & 7286 (1) & $6945(2)$ & $4.66(5)$ \\
\hline$C(32)$ & 4902 (2) & $6746(1)$ & $4380(4)$ & $3.21(4)$ \\
\hline $\mathrm{C}(33)$ & $6111(5)$ & $6729(1)$ & $3262(5)$ & $5.38(7)$ \\
\hline $\mathrm{O}(25)$ & $7271(2)$ & $6342(1)$ & 3978 (4) & $6.05(6)$ \\
\hline
\end{tabular}


Fig. 3. Valence angles $\left({ }^{\circ}\right)$ of both molecules $(I)(a$ and $b)$ in the asymmetric unit. Max. esd's are $0.3^{\circ}$.

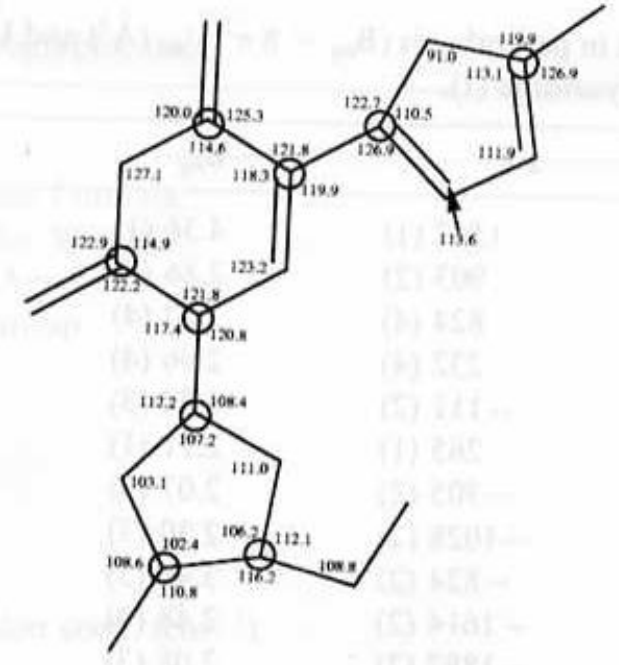

a

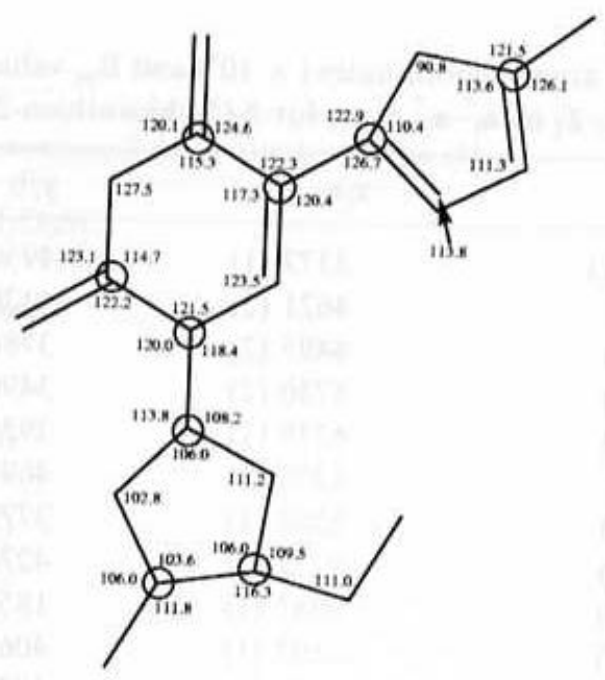

b

Fig. 4. Stereoview of molecular conformation and crystal packing of 5-(5-chlorothicn-2-yI)-2'-deoxyuri-dine (I).
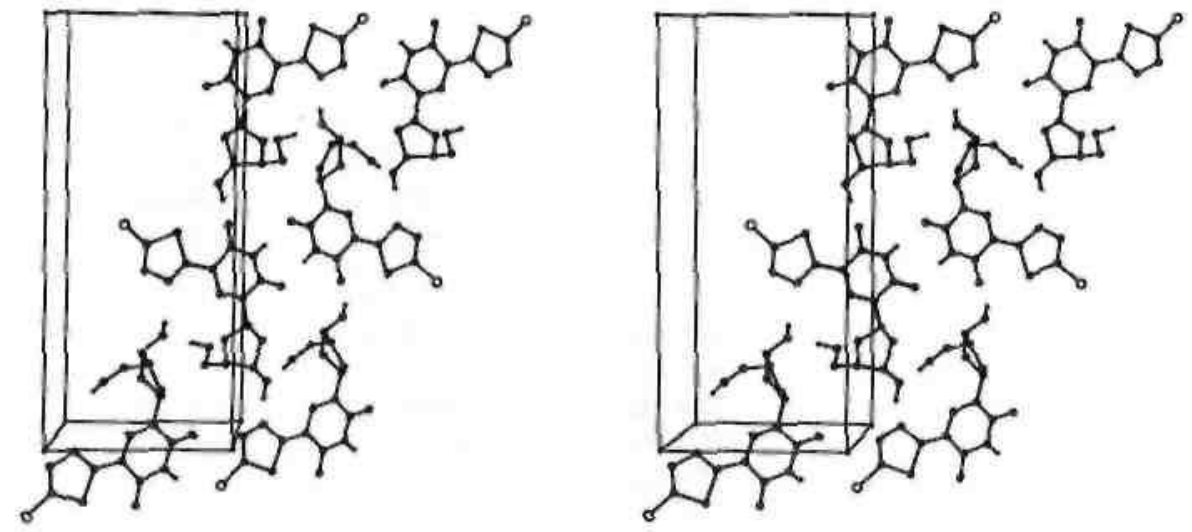

Fig. 5. $S \cdots O$ close contact characterized by a planar five-membered ring. $X=O . N, C$ or $S, B$ and $Y=C\left(s p_{2}\right)$ or $N\left(s p_{2}\right), A=C, Z=O, N, C$ or $H$.<smiles>[Z][Y]1=BOS([X])=CC1</smiles> 
Table 4: Hydrogen bonds ( hydrogen bonds implicated in dimers)

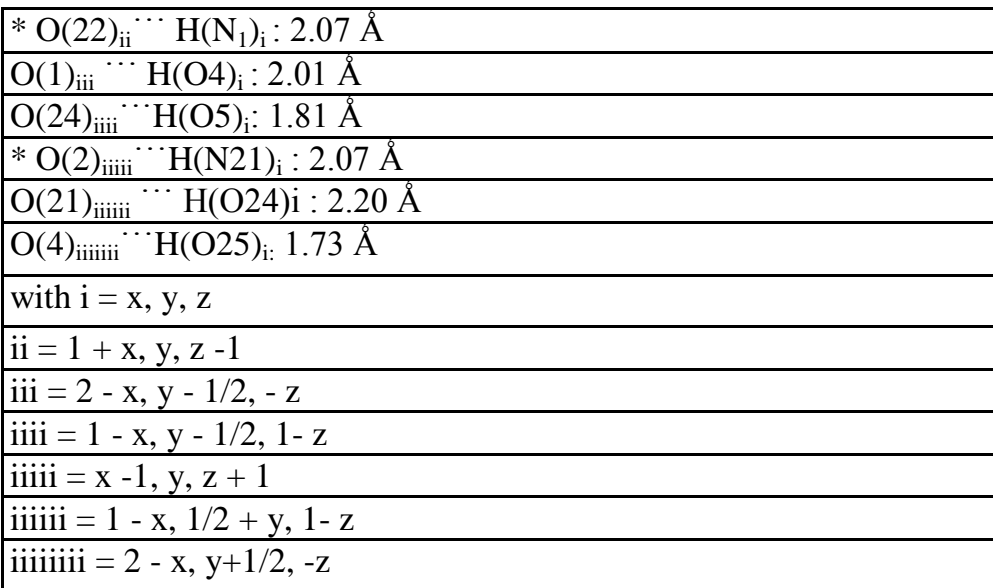

Fig. 6. Stereoview of dimers with vibration ellipsoids (probability: 50\%) formed by the two molecules of the asymmetric unit. Dotted lines represent hydrogen bonds.
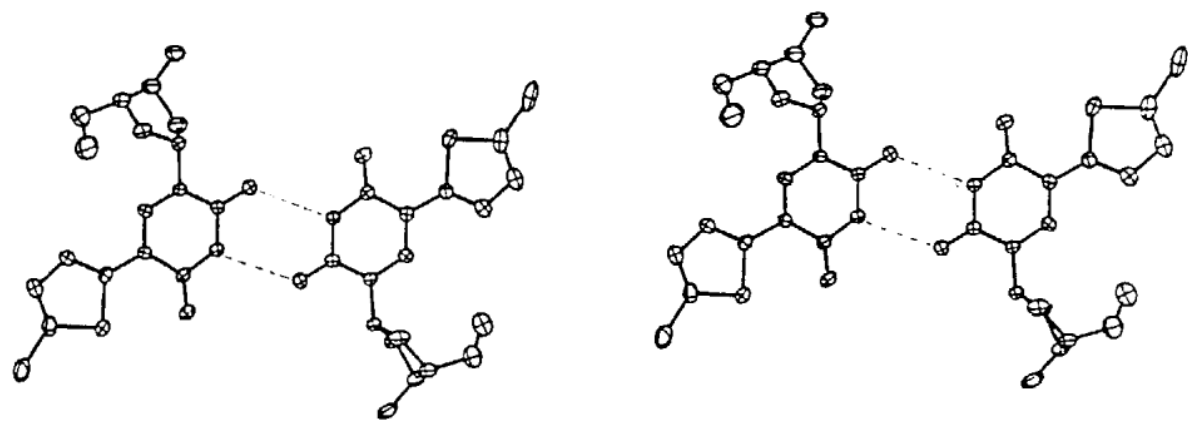

Table 5 Affinity and energy of frontier orbitals homo and lumo for all compounds

\begin{tabular}{|l|l|l|l|}
\hline CompoundsAffinity & homo & lumo & \\
\hline & $(\mu \mathrm{M})$ & $(\mathrm{eV})$ & $(\mathrm{eV})$ \\
\hline 5-(2-bromovinyl)-2'-dUrd (VI) & 0,3 & -6.42790 & 5.61762 \\
\hline 5-(5-chlorothien-2-yl)-2'-dUrd(I) & 2.3 & -5.87846 & 5.30672 \\
\hline 5-(furan-2-yl)-2'-dUrd (II) & 2.9 & -5.90104 & 5.85453 \\
\hline 5-(3-bromoisoxazol-5-yl)-2'-dUrd (V) & 34 & -6.81115 & 5.02058 \\
\hline 5-(isoxazol-5-yl)-2'-dUrd (IV) & 36 & -6.55547 & 5.28714 \\
\hline 5-5-bromofuran-2-yl)-2'-dUrd(II) & 51 & -6.09960 & 5.53248 \\
\hline dUrd = deoxyuridine & & & \\
\hline
\end{tabular}

Table 6 Torsion angles between the 5-membered heterocyclic ring and uracil base

\begin{tabular}{|l|l|}
\hline Compounds & Values (degrees) \\
\hline 5-(5-chlorothien-2-yl)-2'-dUrd(I) & -0.7 \\
\hline 5-(furan-2-yl)-2'-dUrd (II) & 179.7 \\
\hline 5-(isoxazol-5-yl)-2'-dUrd (IV) & 174.5 \\
\hline 5-(5-bromofuran-2-yl)-2'-dUrd(II) & 174.8 \\
\hline dUrd = deoxyuridine & \\
\hline
\end{tabular}


Published in : Antiviral Research (1994), vol. 24, 289-304

Status : Postprint (Author's version)

Fig. 7. Stereoview of the superimposition of the 5-(5-chlorothien-2-yl)-2'-deoxyuridine (I) and BVDU(VI).

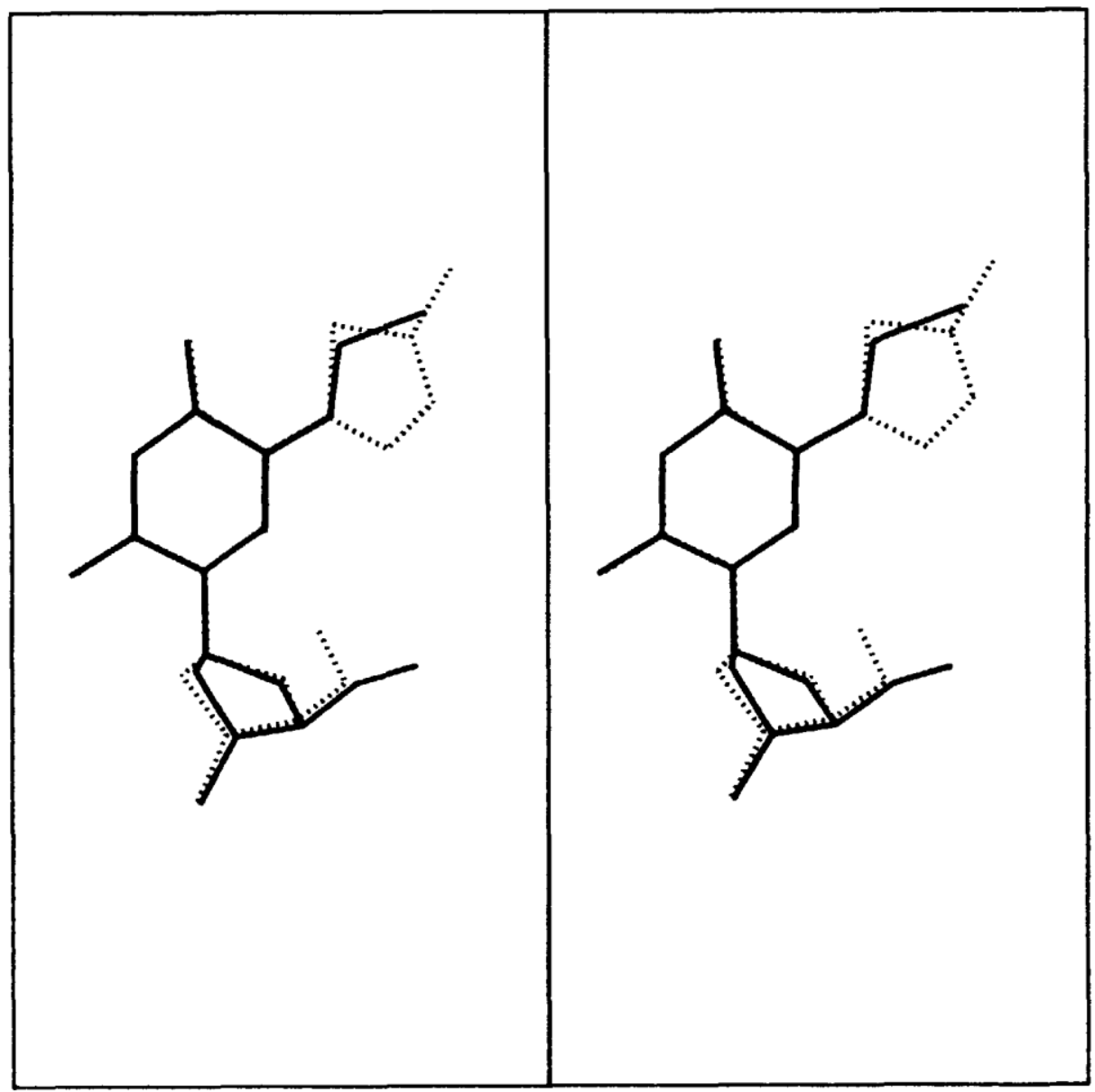


Fig. 8. Molecular electrostatic maps at $1.75 \AA$ Aor (I). 5-(5-chlorothien-2-yl)-2'-deoxyuridine (II). 5-(furan-2-yl)2'-deoxyuridine. (III). 5-(5-bromofuran-2-yl)-2'-deoxyuridinc, (V). 5-(3-bromoisoxazol-5-yl)-2'-deoxyuridinc, (VI). 5-(2-bromovinyl)-2'-deoxyuridine. Positive and negative equipotential contours are plotted in solid and dotted lines, respectively.
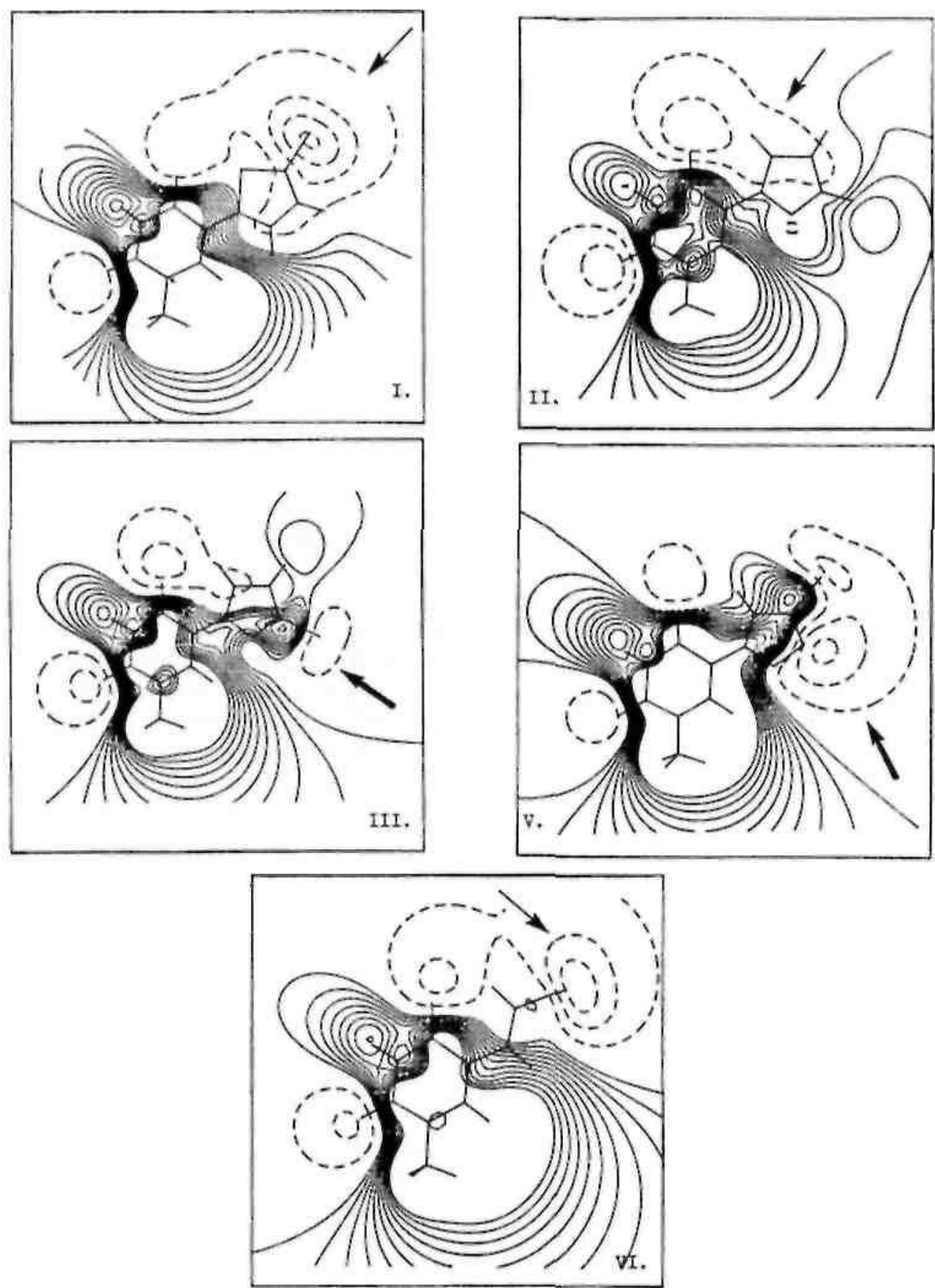


\subsection{Electronic analysis}

(1) Topology and energy of frontier orbitals. In order to explain the affinity of the compounds, we analyzed the topology of the highest occupied and the lowest unoccupied molecular orbitals (homo and lumo, respectively). This property allows to vizualize the electronic density implied in charge transfer interactions. Both are II orbitals, only the $2 \mathrm{p}$ atomic orbitals, perpendicular to the molecular plane, contribute to this electron density.

The topology of the homo and lumo is similar for all compounds (the contour maps are available from the authors).

The energies of these frontier orbitals are summarized in Table 5. The energy of both homo and lumo does not seem to be strongly affected by changing the nature of the atoms in the five-membered cycle.

This approach gave no useful results about structure-activity relationship.

(2) Molecular electrostatic potential (MEP) iso-contour maps. The ab initio STO-3G MEP plots of all the compounds and BVDU in the $x / y$ plane $(z=0)$ and at distances of $1,75 \AA$ from the plane, are shown in Fig. 9 and 8 , respectively. This distance is close to the van der Waals radius and allows us to appreciate the electronic profile perceived by a partner in interaction. Negative equipotential map contours, describing attractive interaction energies for the proton, are plotted in dotted lines. Positive equipotential contours are plotted in solid lines. The contour-to-contour interval for the negative and positive iso-contours are 5 and $1 \mathrm{kcal} \mathrm{mol}^{-1}$, respectively.

In the plane of all compounds, we observed two attractive zones (by order of $-50 \mathrm{kcal} \mathrm{mol}^{-1}$ ) induced by the carbonyls of the uracil cycle (Fig. 9, $\rightarrow$ ) and a large repulsive zone which is spread so as to form an inclusion between attractive zones. The presence of a chlorine and a bromine atom induces a wider attractive zone for chlorothienyl (I) and BVDU (VI). For furanyl (II), there is another attractive zone $\left(-30 \mathrm{kcal} \mathrm{mol}^{-1}\right)$ due to the presence of an oxygen atom (Fig. $9, \rightarrow$ ). This zone is more important $\left(-50 \mathrm{kcal} \mathrm{mol}^{-1}\right)$ for bromofuranyl (III), isoxazolyl (IV) and bromoisoxazolyl (V) (Fig. 9, $\rightarrow$ ).

At $1.75 \AA$, the attractive influence of the two carbonyl groups is reduced $\left(-10 \mathrm{kcal} \mathrm{mol}^{-1}\right)$. For chlorothienyl (I), furanyl (II) and BVDU (VI) (Fig. 8, $\rightarrow$ ) the zone induced by the carbonyl in position 4 is spread above the fivemembered cycles, while the six-membered cycles are covered by a repulsive zone. On the contrary, a repulsive zone almost completely covers bromofuranyl (III), isoxazol (IV) and bromoisoxazol (V). As in the plane of the compounds, we observed another attractive zone for bromofuranyl (III), isoxazolyl (IV) and bromoisoxazolyl (V) $\left(-25 \mathrm{kcal} \mathrm{mol}^{-1}\right)$ and for furanyl (II) $\left(-5 \mathrm{kcal} \mathrm{mol}^{-1}\right)($ Fig. $8, \rightarrow)$. 
Fig. 9. Molecular electrostatic maps at 0 Á for (I). 5-(5-chlorothien-2-yl)-2'-deoxyuridine. (II). 5-(furan-2-yl)-2'deoxyuridine. (III). 5-(5-bromofuran-2-yl)-2'-deoxyuridine, (V). 5-(3-bromoisoxazol-5-yl)-2'-deoxyuridine. (VI). 5-(2-bromovinyl)-2'-deoxyuridine. Positive and negative equipotential contours are plotted in solid and dotted lines, respectively.
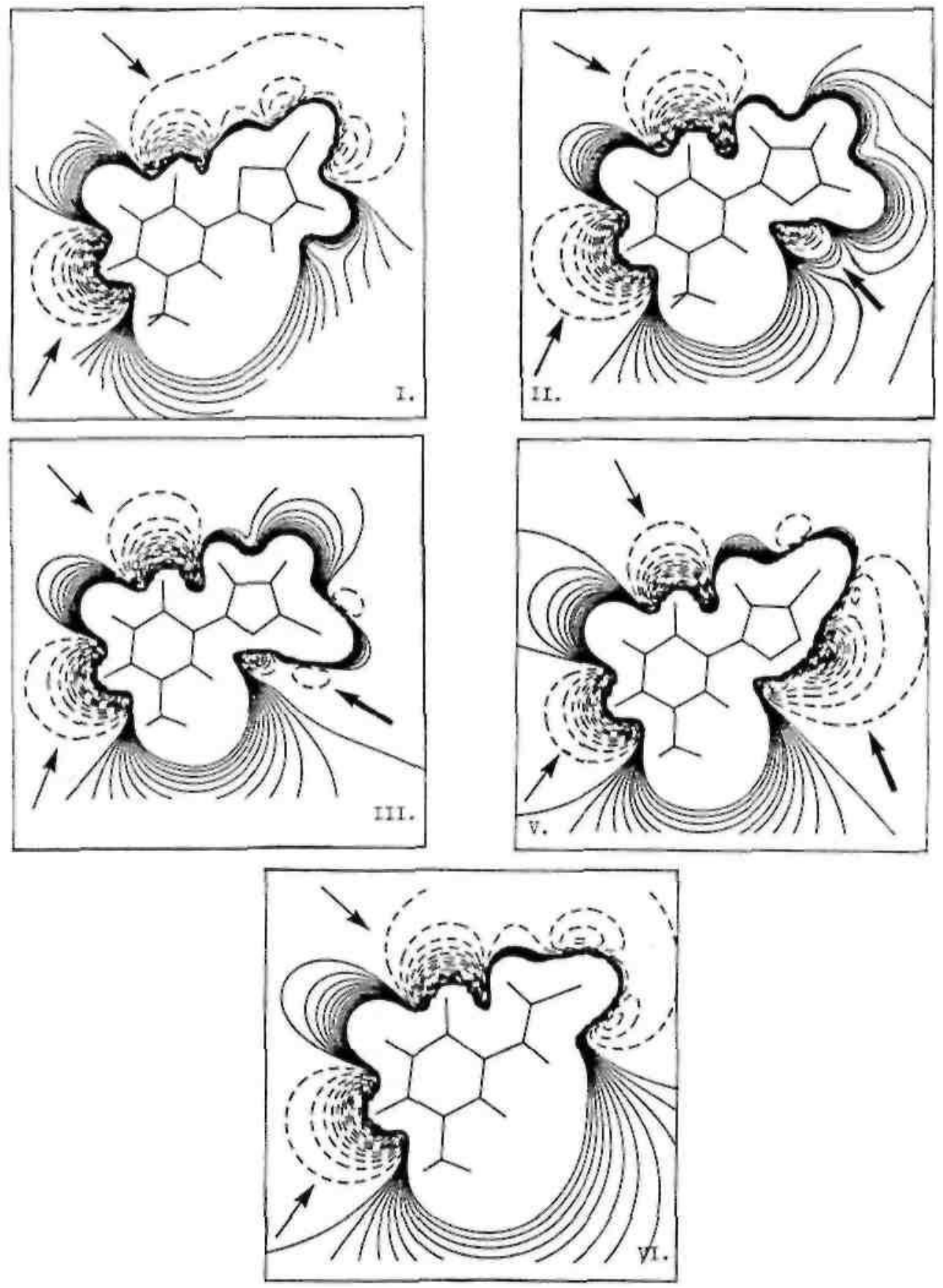


\section{Discussion}

In order to explain the structure-activity relationships of all the compounds, we studied various properties: the crystallographic structure, the steric effects, the topology and the energy of frontiers orbitals, and the potential electrostatic maps.

X-ray structure analysis of five different 5-substituted-2'-deoxyuridines revealed that all compounds have a quasi-coplanar geometry between the 5-membered heterocyclic ring and uracil base (Table 6). The orientation, however, of the five membered ring is different. The oxygen atom of the furanyl ring and the isoxazolyl ring is pointed to the opposite direction than the sulfur atom of the thienyl ring. The asymmetric unit is formed by dimers similar to the ones observed between two DNA bases. An even more pronounced difference is observed when comparing the molecular electrostatic potential iso-contour maps of these compounds at a distance of 1.75 $\AA$ Above the ring. A large negative region is located above the 5-membered heterocycle and a large positive region above the uracil ring of the compound which are good substrates of the viral TK. In contrast, the positive region is situated above the whole molecule (except for the nitrogen atom of the isoxazolyl ring) of the compounds which are poor substrates for the viral TK. This observation was confirmed by calculating the molecular electrostatic potential maps for 5-(2-bromovinyl)-2'-deoxyuridine (VI). The presence of an attractive region $1.75 \AA$ above the 5-membered heterocycle seems to be important for the binding to the enzyme. On the other hand, the presence of an important attractive $\left(-50 \mathrm{kcal} \mathrm{mol}^{-1}\right)$ zone at $0 \AA \AA$ around the inferior part of the five-membered heterocycle seems to be incompatible with the binding to the enzyme. This study led to a better insight in the structural requirements of 5-substitued-2'-deoxynucleosides to be accepted as substrates for HSV-1 thymidine kinase and can be considered as an important contribution to the development of new selective antiHSV-1 agents.

\section{Acknowledgements}

The authors acknowledge the National Belgian Foundation for Scientific Research (FNRS), IBM-Belgium, and the Facultes Universitaires Notre-Dame de la Paix for the use of the Namur Scientific computing facility. A.O. thanks B. Norberg for helpful collaboration.

\section{References}

Angyan, J.G., Poirier, R.A., Kucsman, A. and Csizmadia, I.G. (1987) Bonding between nonbonded sulfur and oxygen atoms in selected organic molecules (A Quantum Study). J. Am. Chem. Soc. 109, 2237-2245.

Baudoux, G. and Vercauteren, D.P. (1989) CPS, a contouring plotting system, Facultes Universitaires Notre-Dame de la paix, Namur.

Bohman, C, Balzarini, J., Wigerinck, P., Van Aerschot, A., Herdewijn, P. and De Clercq, E. (1993) Mechanistic study on the antiviral and cytostatic effects of 5-thien-2-yl and 5-furan-2-yl substituted pyrimidine nucleoside analogues. 4th Symposium of the European Society for the study of Purine and Pyrimidine Metabolism in Man. Nijmegen, The Netherlands, 31 Aug.-3 Sept.

Bradshaw, Jr.H.D. and Deininger, P.L. (1984) Human thymidine kinase gene: molecular cloning and nucleotide sequences of a cDNA expressible in mammalian cells. Mol. Cell. Biol. 4, 2316-2320.

Coen, D.M. (1991) The implication of resistance to antiviral agents for herpes virus drug targets and drug therapy. Antiviral Res. 15, 187300 .

Collins, J., Schleyer, P., Binkley, J.S. and Pople, J.A. (1976) Self-consistent molecular orbital methods. XVII. Geometries and binding energies of second-row molecules. A comparison of three basis sets. J. Chem. Phys. 64, 5142-5151.

Enquist, L.W., Vandewoude, G.F., Wagner, M., Smiley, J.R. and Summers, W.C. (1979) Construction and characterization of a recombinant plasmid encoding the gene for the thymidine kinase of herpes simplex type 1 virus. Gene 7, 335-342.

Folkers, G., Trumpp-kallmeyer, S., Gutbrod, O., Krickl, S., Fetzer, J. and Keil, G.M. (1991) Computer-aided active-site-directed modeling of the herpes simplex virus 1 and thymidine kinase. J. Comp. Aided Mol. Design 5, 387-404.

Flemington, E., Bradshaw, Jr. H.D., Traina-Dorge, V., Slagel, V. and Deininger, P.L. (1987) Sequence, structure and promotor characterization of the thymidine kinase gene. Gene 52, 267-277. 
Published in : Antiviral Research (1994), vol. 24, 289-304

Status : Postprint (Author's version)

Frisch, M.J., Binkley, J.S., Schlegel, H.B., Raghavachari, K., Melius, C.F., Martin, R.L., Stewart, J.J.P., Bobrowicz, F.W., Rohfling, C.M., Kahn, L.R., Defrees, D.J., Seeger, R., Whiteside, R.A., Fox, D.J., Fleuder, E.M. and Pople, J.A. (1988) GAUSSIAN 86 (Carnegie-Mellon Quantum Chemistry Publishing Unit, Pittsburgh, PA).

Hehre, W.J., Stewart, R.F. and Pople, J.A. (1969) Self-consistent Molecular-Orbital Methods. I. Use of Gaussian Expansions of Slater-type Atomic Orbitals. J. Chem. Phys. 51, 2657-2664.

Hinde, R.J., Luken, W.L. and Chin, S. (1988) "Moplot", IBM Kingston Technical Report KGN-141, New York.

Johnson, C.K. (1976) ORTEP Report ORNL-5138, Oak Ridge National Laboratory, Oak Ridge, Tennesse, USA.

Kalman, A. and Parkanyi, L. (1980) Structure of 2-benzolimino-3-methyl-1,3-thiazolidine: A comparison of intramolecular X-S O = Y interactions. Acta Cryst. B36, 2372-2378.

Leib, D.A., Ruffner, K.L., Hildebrand, C, Schaffer, P.A., Wright, G.E. and Coen, D.M. (1990) Specific inhibitors of herpes simplex thymidine kinase diminish reactivation of latent virus from explanted murine ganglia. Antimicr. Ag. Chemother. 34, $1285-1286$.

Lozac'h, N. (1971) Adv. Heterocycl. Chem. 13, 161-234.

Parkanyi, L., Kalman, A., Kovacs, T., Szaboles, A. and Otvos, L. (1983) Crystal and molecular structure of (£)-5-(2-bromovinyl)-2'deoxyuridine. Nucl. Acids Res. 11, 7999.

Parkanyi, L., Kalman, A., Czugler, M., Kovacs, T. and Walker, R.T. (1987) A comparison of the conformations adopted by some 5bromovinyl-2'-deoxyuridine and a correlation with their antiviral properties: an X-ray study. Nucl. Acids Res. 15, $4111-4121$.

Sanderson, M.R., Freemont, P.S., Murthy, H.M.K., Krane, J.F., Summers, W.C. and Steitz, T.A. (1988) Purification and crystallization of thymidine kinase from herpes simplex virus type 1. J. Mol. Biol. 202, 917-919.

Sheldrick, G.M. (1976) SHELX76. Program for crystal structure determination. Univ. of Cambridge, UK.

Sheldrick, G.M. (1986) SHELX86. Program for the solution of crystal structures. Institut fur Anorganische Chemie der Universitat, Gottingen, Germany.

Spek, A.L. (1990) PLATON92. Acta Cryst. A 46, C3

Vanderveken, D.J. and Vercauteren, D.P. (1989) KEMIT, a Molecular Graphics System, Rel 1.2., Facultes Universitaires Notre-Dame de la Paix, Namur.

Wigerinck, P., Pannecouque, C, Snoeck, T., Claes, P., De Clercq, E. and Herdewijn, P. (1991a) 5-(5- Bromothien-2-y])-2'-deoxyuridine and 5-(5-chlorothien-2-yl)-2'-deoxyuridine are equipotent to (£)-5- (2-bromovinyl)-2'-deoxyuridine in the inhibition of herpes simplex virus type1 replication. J. Med. Chem. 34, 2383-2389.

Wigerinck, P., Snoeck, R., Claes, P., De Clercq, E. and Herdewijn, P. (1991b) Synthesis and antiviral activity of 5-heteroaryl substituted 2'deoxyuridine. J. Med. Chem. 34, 1767-1772.

Wigerinck, P., Kerremans, L., Claes, P., Snoeck, R., Maudgal, P., De Clercq, E. and Herdewijn, P. (1993) Synthesis and antiviral activity of 5-thien-2-yl-2'-deoxyuridine analogues. J. Med. Chem. 31, 538-543. 